\title{
Stereospecific, Ligand-Free Synthesis of All-Carbon Quaternary Ste- reocenters from Tertiary Benzylic Carboxylates
}

\author{
Jianyu Xu, Sarah M. Pound, Corey H. Basch, Alana D. Duke, Mary P. Watson* \\ Department of Chemistry \& Biochemistry, University of Delaware, Newark, Delaware 19716, United States \\ Supporting Information Placeholder
}

\begin{abstract}
Nickel-catalyzed, stereospecific cross-couplings via activation of secondary $\mathrm{C}-\mathrm{O}$ bonds has been well developed in the past few years. Meanwhile, stereospecific cross-couplings of tertiary electrophiles have been rarely explored. Herein, we describe a nickel-catalyzed, ligand-free Suzuki-Miyaura vinylation, using easily prepared, highly enantioenriched tertiary benzylic carboxylates to install all-carbon quaternary stereocenters in high yields and ee's. In addition to allowing stereospecific vinylation of these substrates for the first time, this method overcomes the longstanding requirement for a naphthyl group on the benzylic carboxylate.
\end{abstract}

Harnessing tertiary electrophiles in transition metal-catalyzed carbon-carbon $(\mathrm{C}-\mathrm{C})$ bond formation is one of the longstanding challenges in modern chemistry. ${ }^{1}$ Because these transformations would deliver valuable, all-carbon quaternary centers, which are widespread in natural products and other bioactive compounds, ${ }^{2}$ tremendous effort has been directed towards this goal. ${ }^{3,4}$ The challenge of such cross-couplings are two-fold; significant steric hindrance must be overcome, and stereochemistry must be controlled. With respect to overcoming the steric challenge, unactivated alkyl halides are well-developed tertiary electrophiles. ${ }^{5}$ Other tertiary electrophiles have also been demonstrated, such as benzylic aziridines, ${ }^{6}$ benzylic sulfonates, ${ }^{7}$ redox-active esters, ${ }^{8}$ and unactivated tertiary alkyl oxalates ${ }^{9}$ (Scheme 1A). However, in terms of stereocontrol, only a few, limited methods are known, particularly for non-allylic substrates. ${ }^{10}$ Namely, Fu and Zhang have developed enantioconvergent cross-couplings of tertiary lactam bromides $^{11}$ and oxindole epoxides ${ }^{12}$, respectively (Scheme 1B). The strict requirements for the substrate structure in these reactions belies the difficulty in controlling the stereochemistry in cross-couplings of tertiary electrophiles. In an alternative strategy, we developed a stereospecific SuzukiMiyaura arylation of enantioenriched tertiary benzylic acetates (Scheme 1C).${ }^{13}$ However, as excited as we were to form benzylic quaternary stereocenters using this $\mathrm{NiCl}_{2} \cdot \mathrm{DME} / \mathrm{CyJohnPhos}$ catalyst, we were sharply aware of its limitations. Although vinylboronates are often more reactive than their aryl counterparts, we surprisingly observed no reaction when the arylation conditions were applied to vinylboronates. The arylation was also sensitive to the steric bulk of the boronate ester. Neopentyl glycol esters (Bneop) were required, because the more common pinacol esters (Bpin) resulted in lower yields, thus limiting the convenience of this method. In addition to these major limitations in the nucleophilic coupling partner, the scope of benzylic acetates was limited to those with naphthyl (or naphthyl-like) substituents. In fact, only one substrate lacked such substitution, and it was a dibenzylic substrate. Notably, this requirement for a naphthyl group or dibenzylic activation plagues stereospecific crosscouplings as a whole, including those of secondary electrophiles. ${ }^{14-19}$

\section{Scheme 1. Tertiary Electrophiles in Cross-Couplings}

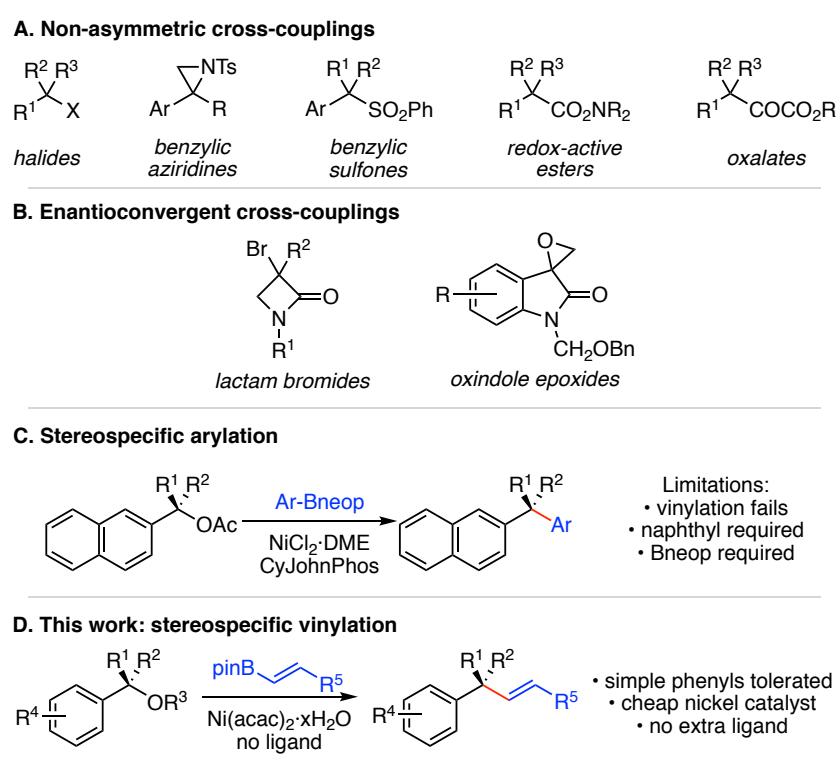

Due to these limitations, the importance of all-carbon quaternary stereocenters, and the high utility of vinyl substituents for further elaboration, we now report a stereospecific, nickelcatalyzed cross-coupling of tertiary benzylic carboxylates (Scheme 1D). To enable this vinylation, a new catalyst system - one unsupported by any added ligand - was discovered. This new catalyst system not only enabled the vinylation; it also resulted in unprecedented scope in the tertiary benzylic 
carboxylate, allowing even substrates with simple phenyl substituents to be used.

We selected the cross-coupling of tertiary acetate $\mathbf{1 a}$ and vinyl boronate ester $\mathbf{2} \mathbf{a}$ for optimization studies (Table 1). Under similar conditions as our previous arylation $\left(\mathrm{NiCl}_{2} \cdot \mathrm{DME}\right.$, CyJohnPhos), we saw only trace desired product 3 (entry 1 ). A broad investigation of ligands showed that bulkier Buchwald-type ligands gave better yields, with XPhos providing $80 \%$ yield (entries $2-3$ ). However, we observed even better yield in the absence of ligand (entry 4 ). This surprising result was mechanistically intriguing and offered an opportunity to develop an inexpensive and simple catalyst. Indeed, we were able to use an even cheaper nickel catalyst, $\mathrm{Ni}(\mathrm{acac})_{2} \cdot \mathrm{xH}_{2} \mathrm{O},{ }^{20}$ by changing the base from $\mathrm{NaOMe}$ to $\mathrm{LiO} t$ - $\mathrm{Bu}$ (entries 5-6). Control experiments (entries 7-8) showed that both nickel and base were required. Additionally, the corresponding vinyl Bneop (2b) worked (entry 9). However, use of boronic acid $2 \mathbf{c}$ resulted in no product (entry 10 ), and only $34 \%$ yield was observed with trifluoroborate $\mathbf{2 d}$ (entry 11).

Table 1. Optimization ${ }^{a}$

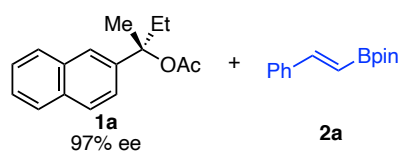

$\underset{\substack{\text { 2-Me-THF }(0.2 \mathrm{M}) \\ 50^{\circ} \mathrm{C}, 24 \mathrm{~h}}}{\substack{\text { Ni source }(10 \mathrm{~mol} \%) \\ \text { ligand, base }}}$

\begin{tabular}{|c|c|c|c|c|c|}
\hline $\begin{array}{l}\text { en- } \\
\text { try }\end{array}$ & $\mathrm{Ni} / \mathrm{L}$ & base & $\begin{array}{l}\text { yield } \\
(\%)^{b}\end{array}$ & $\begin{array}{l}\text { ee } \\
(\%)^{c}\end{array}$ & $\begin{array}{c}\text { es } \\
(\%)^{d}\end{array}$ \\
\hline 1 & $\begin{array}{l}\mathrm{NiCl}_{2} \cdot \mathrm{DME} / \\
\text { CyJohnPhos }\end{array}$ & $\begin{array}{l}\mathrm{Na}- \\
\mathrm{OMe}\end{array}$ & $<5$ & n.d. ${ }^{e}$ & n.d. \\
\hline 2 & $\begin{array}{c}\mathrm{NiCl}_{2} \cdot \mathrm{DME} / \\
\text { SPhos }\end{array}$ & $\begin{array}{l}\mathrm{Na}- \\
\mathrm{OMe}\end{array}$ & 7 & 96 & 99 \\
\hline 3 & $\begin{array}{c}\mathrm{NiCl}_{2} \cdot \mathrm{DME} / \\
\text { XPhos }\end{array}$ & $\begin{array}{l}\mathrm{Na}- \\
\mathrm{OMe}\end{array}$ & 80 & 96 & 99 \\
\hline 4 & $\mathrm{NiCl}_{2} \cdot \mathrm{DME}$ & $\begin{array}{l}\mathrm{Na}- \\
\mathrm{OMe}\end{array}$ & $>99$ & 97 & $>99$ \\
\hline 5 & $\mathrm{Ni}(\mathrm{acac})_{2} \cdot \mathrm{xH}_{2} \mathrm{O}$ & $\begin{array}{l}\mathrm{Na}- \\
\mathrm{OMe}\end{array}$ & 91 & 93 & 96 \\
\hline 6 & $\mathrm{Ni}(\mathrm{acac})_{2} \cdot \mathrm{xH}_{2} \mathrm{O}$ & $\begin{array}{c}\mathrm{LiO} t- \\
\mathrm{Bu}\end{array}$ & $>99$ & 97 & $>99$ \\
\hline 7 & none & $\begin{array}{c}\mathrm{LiO} t- \\
\mathrm{Bu}\end{array}$ & 0 & n.d. & n.d. \\
\hline 8 & $\mathrm{Ni}(\text { acac })_{2} \cdot \mathrm{xH}_{2} \mathrm{O}$ & none & 0 & n.d. & n.d. \\
\hline $9^{f}$ & $\mathrm{Ni}(\mathrm{acac})_{2} \cdot \mathrm{xH}_{2} \mathrm{O}$ & $\begin{array}{c}\mathrm{LiO} t- \\
\mathrm{Bu}\end{array}$ & 86 & 96 & 99 \\
\hline $10^{g}$ & $\mathrm{Ni}(\mathrm{acac})_{2} \cdot \mathrm{xH}_{2} \mathrm{O}$ & $\begin{array}{c}\mathrm{LiO} t- \\
\mathrm{Bu}\end{array}$ & 0 & n.d. & n.d. \\
\hline $11^{h}$ & $\mathrm{Ni}(\mathrm{acac})_{2} \cdot \mathrm{xH}_{2} \mathrm{O}$ & $\begin{array}{c}\mathrm{LiO} t- \\
\mathrm{Bu}\end{array}$ & 34 & 92 & 95 \\
\hline
\end{tabular}
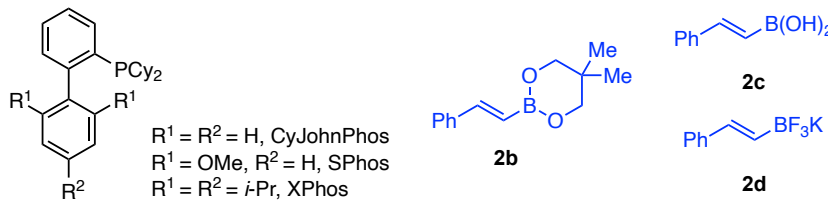

${ }^{a}$ Conditions: 1a $(0.10 \mathrm{mmol}), \mathbf{2 a}(2.0$ equiv), Ni source (10 mol \%), ligand (20 mol \%), base (2.0 equiv), 2-Me-THF $(0.2 \mathrm{M}), 50{ }^{\circ} \mathrm{C}, 24 \mathrm{~h}$, unless otherwise noted. ${ }^{b}$ Determined by ${ }^{1} \mathrm{H}$ NMR analysis using 1,3,5-trimethoxybenzene as internal standard. ${ }^{c}$ Determined by HPLC analysis using a chiral stationary phase. ${ }^{d}$ es $=$ ee $_{\text {product }} /$ ee $_{\text {starting material. }}{ }^{e}$ n.d. $=$ not determined. ${ }^{f} \mathbf{2} \mathbf{b}$ in place of $\mathbf{2 a} .^{g} \mathbf{2}$ in place of $\mathbf{2 a} .{ }^{h} \mathbf{2 d}$ in place of $\mathbf{2 a}$.

Under the optimized conditions (Table 1, entry 6), we observed a broad scope with respect to the vinyl boronate ester (Scheme 2). Vinyl groups with both aryl (3-8) and alkyl groups (9-14) can be incorporated. Electron-rich (4) and electron-poor $(\mathbf{5}, \mathbf{6})$ aryl substituents worked well. Compatibility with a range of functional groups was also observed. Noteworthy examples include an ester (6), aryl chlorides (7, 8), a TBS-protected alcohol (9), and an alkyl chloride (10), which offer opportunities for further elaboration. Notably, a tremendous range of vinyl substitution is tolerated, enabling synthesis of monosubstituted alkene 11, 1,1-disubstituted alkene 13, and even sterically encumbered trisubstituted alkenes 12 and 14. Notably, these more substituted alkenes are not accessible via an allylic arylation. ${ }^{21}$ In all cases, the stereochemical fidelity was exceptional.

\section{Scheme 2. Scope of the Vinyl Boronate Ester}

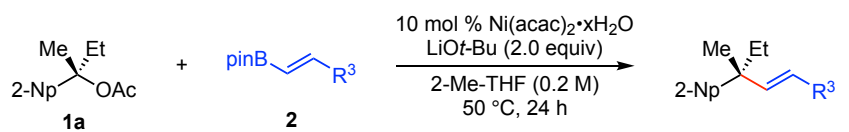

$$
\begin{aligned}
& 3,98 \% \\
& 96 \% \text { ee, }>99 \% \text { es }
\end{aligned}
$$

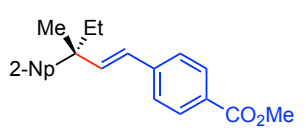

6, $79 \%$

$$
\begin{aligned}
& \mathbf{6}, 79 \% \\
& 96 \% \text { ee, } 99 \% \text { es }
\end{aligned}
$$

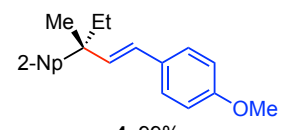

$$
\text { 4, 99\% }
$$

$$
97 \% \text { ee, }>99 \% \text { es }
$$
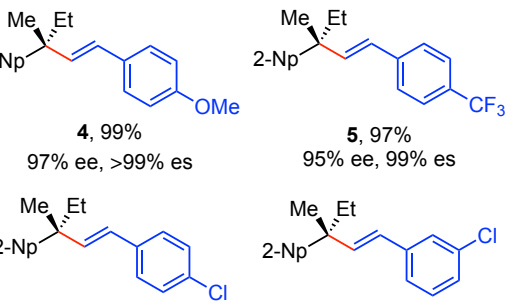

$\mathbf{5}, 97 \%$
$95 \%$
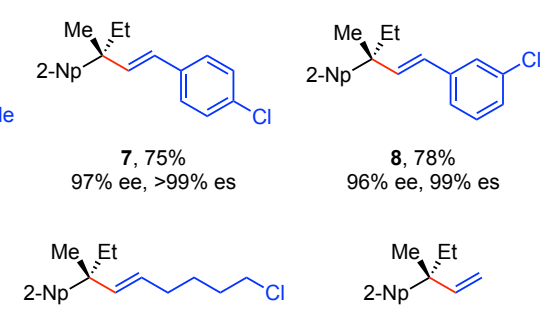

$$
\text { 9->99\% }
$$
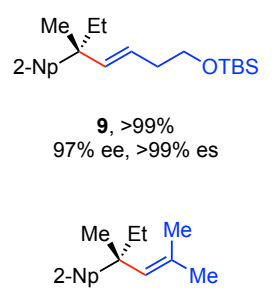$$
\begin{gathered}
10,99 \% \\
97 \% \text { ee, }>99 \% \text { es }^{b}
\end{gathered}
$$

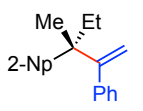

$13,75 \%$
$97 \%$ ee, $>99 \%$ es

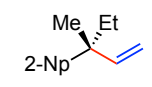

$11,93 \%$

95\% ee, $98 \%$ es

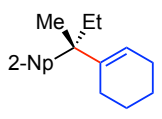

$14,89 \%$ $96 \%$ ee, $>99 \%$ es 
${ }^{a}$ Conditions: $1 \mathrm{a}(0.40 \mathrm{mmol}), \mathbf{2}(2.0$ equiv $), \mathrm{Ni}(\mathrm{acac})_{2} \cdot \mathrm{xH}_{2} \mathrm{O}$ ( $10 \mathrm{~mol} \%), \mathrm{LiO} t$-Bu (2.0 equiv), 2-Me-THF ( $0.2 \mathrm{M}), 50^{\circ} \mathrm{C}, 24$ h. Average isolated yields $( \pm 3 \%)$ and ee's $( \pm 1 \%$, determined by HPLC or SFC analysis using a chiral stationary phase) of duplicate experiments. ${ }^{b} 80^{\circ} \mathrm{C}$.

With respect to the scope of tertiary benzylic esters, we were particularly interested in substrates with heteroaryl and non-naphthyl aryl groups, because these substrates failed under our previous arylation conditions (Scheme 3). Excitingly, heteroaryl substitution is well tolerated, as evidenced by the efficient formation of benzofurans 15 and 16, indole 17, and quinoline 18. For substrates with non-naphthyl groups, we observed low yields when we employed benzylic acetates as substrates. However, we also observed decomposition of these tertiary benzylic acetates upon purification, leading us to question whether they were simply decomposing under the reaction conditions, particularly if they underwent slower oxidative addition than naphthyl-substituted 1a. By changing to a more stable pivalate group, we were able to break through the limitation of naphthyl-like substrates. Using pivalates and increasing the reaction temperature to $80^{\circ} \mathrm{C}$ enabled efficient cross-couplings of simple phenyl-substituted esters (19-21). Additionally, more sterically hindered quaternary centers (22, 23) were also accessible. The ability to incorporate heteroaryls and non-naphthyl substituents dramatically expands the utility of this method.

\section{Scheme 3. Ester Scope}

$$
\text { OMe }
$$

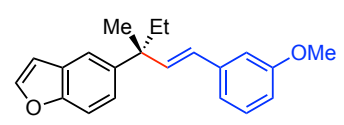

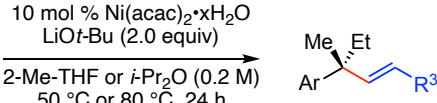

$15,95 \%$

$94 \%$ ee, $>99 \%$ es

$\mathrm{R}=\mathrm{Ac}, 94 \%$ ee

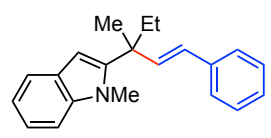

$17,61 \%$ $93 \%$ ee, $94 \%$ es $^{b}$ $\mathrm{R}=\mathrm{Ac},>99 \%$ ee
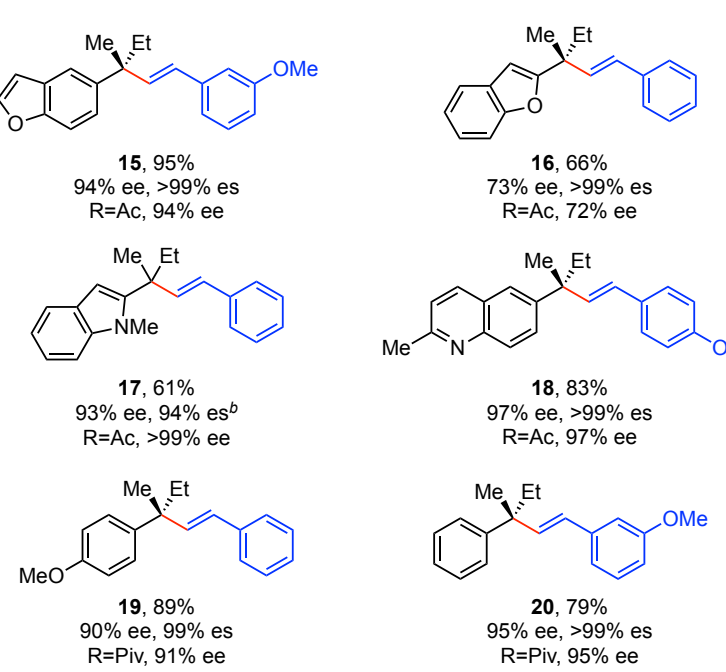

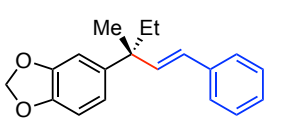

21, $78 \%$

$95 \%$ ee, $>99 \%$ es

R=Piv, $93 \%$ ee

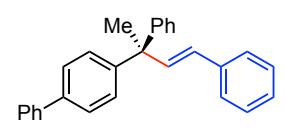

22, $67 \%$ $85 \%$ ee, $93 \%$ es R=Piv, $91 \%$ ee

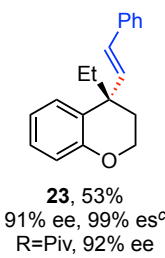

${ }^{a}$ Conditions: $1 \mathrm{a}(0.40 \mathrm{mmol}), \mathbf{2}(2.0$ equiv $), \mathrm{Ni}(\mathrm{acac})_{2} \cdot \mathrm{xH}_{2} \mathrm{O}$ (10 mol \%), $\mathrm{LiOt}$-Bu (2.0 equiv), 2-Me-THF $(0.2 \mathrm{M}), 50{ }^{\circ} \mathrm{C}$ or
$i-\operatorname{Pr}_{2} \mathrm{O}(0.2 \mathrm{M}), 80^{\circ} \mathrm{C}, 24 \mathrm{~h}$. Average isolated yields $( \pm 4 \%)$ and ee's ( $\pm 2 \%$, determined by HPLC or SFC analysis using a chiral stationary phase) of duplicate experiments, unless otherwise noted. ${ }^{b}$ Unknown absolute configuration. ${ }^{c}$ Single run.

In terms of mechanism, we hypothesize that this reaction proceeds via a $\mathrm{Ni}^{\mathrm{O} / \mathrm{II}}$ catalytic cycle, starting with oxidation addition via an $\mathrm{S}_{\mathrm{N}} 2$ '-like attack of a $\mathrm{Ni}^{0}$ species on the benzylic carboxylate. ${ }^{14,17}$ The overall reaction proceeds with stereoretention, ${ }^{22}$ consistent with oxidative addition through a closed transition state with the carboxylate directing $\mathrm{Ni}^{0}$ to the ortho position of the aryl ring. Subsequent transmetallation and reductive elimination delivers product and completes the catalytic cycle. However, it is unclear what species supports the nickel intermediates, particularly $\mathrm{Ni}^{0}$, because no additional ligand is needed. One possible supporting ligand is 1,3-butadiene, which we have observed in low yields and likely form during the reduction of $\mathrm{Ni}$ (acac) ${ }_{2}{ }^{15}$ However, based on precedent for electron-poor alkenes as ligands for $\mathrm{Ni}^{0},{ }^{23}$ the vinylboronate ester or product may also serve as ligand. ${ }^{24}$ Further studies are needed to determine what species is the active catalyst and why this catalyst offers the unprecedented ability to activate non-naphthyl substrates.

In summary, these new conditions enable unparalleled scope in the benzylic carboxylate and the use of widely commercially available vinylboronate esters. Notably, these reactions rely only on inexpensive $\mathrm{Ni}(\mathrm{acac})_{2} \cdot \mathrm{xH}_{2} \mathrm{O}$ as catalyst; no additional ligand is needed. Exploration of the mechanism, especially the nature of the active catalyst, and efforts to expand the use of this highly active catalyst system are ongoing in the lab.

\section{ASSOCIATED CONTENT}

Supporting Information. The Supporting Information is available free of charge on the ACS Publications website. Experimental details and data (PDF)

\section{AUTHOR INFORMATION}

\section{Corresponding Author}

*mpwatson@udel.edu

\section{ACKNOWLEDGMENT}

We thank NIH (R01 GM111820, R35 GM131816) and the University of Delaware for fellowships (C.H.B., A.D.D.). Data were acquired at UD on instruments obtained with assistance of NSF and NIH funding (NSF CHE0421224, CHE1229234, CHE0840401, and CHE1048367; NIH P20 GM104316, P20 GM103541, and S10 OD016267). We thank Lotus Separations, LLC, for assistance with SFC.

\section{REFERENCES}

(1) Choi, J.; Fu, G. C. Transition metal-catalyzed alkyl-alkyl bond formation: Another dimension in cross-coupling chemistry. Science 2017, 356 , eaaf 7230 . 
(2) Quasdorf, K. W.; Overman, L. E. Catalytic enantioselective synthesis of quaternary carbon stereocentres. Nature 2014, 516, 181-191.

(3) For an organocatalytic approach, see: Wendlandt, A. E.; Vangal, P.; Jacobsen, E. N. Quaternary stereocentres via an enantioconvergent catalytic $\mathrm{S}_{\mathrm{N}} 1$ reaction. Nature 2018, 556, 447-451.

(4) For the umpolung approach with a tertiary boronate, see: Bonet, A.; Odachowski, M.; Leonori, D.; Essafi, S.; Aggarwal, V. K. Enantiospecific $s p^{2}$ $s p^{3}$ coupling of secondary and tertiary boronic esters. Nat. Chem. 2014, 6, 584-589.

(5) Zultanski, S. L.; Fu, G. C. Nickel-catalyzed carbon-carbon bondforming reactions of unactivated tertiary alkyl halides: Suzuki arylations. J. Am. Chem. Soc. 2013, 135, 624-627.

(6) Huang, C. Y.; Doyle, A. G. Electron-deficient olefin ligands enable generation of quaternary carbons by Ni-catalyzed cross-coupling. J. Am. Chem. Soc. 2015, 137, 5638-5641.

(7) Ariki, Z. T.; Maekawa, Y.; Nambo, M.; Crudden, C. M. Preparation of Quaternary Centers via Nickel-Catalyzed Suzuki-Miyaura CrossCoupling of Tertiary Sulfones. J. Am. Chem. Soc. 2018, 140, 78-81.

(8) Chen, T. G.; Zhang, H.; Mykhailiuk, P. K.; Merchant, R. R.; Smith, C. A.; Qin, T.; Baran, P. S. Quaternary Centers by Nickel-Catalyzed CrossCoupling of Tertiary Carboxylic Acids and (Hetero)Aryl Zinc Reagents. Angew. Chem., Int. Ed. 2019, 58, 2454-2458.

(9) Ye, Y.; Chen, H.; Sessler, J. L.; Gong, H. Zn-Mediated Fragmentation of Tertiary Alkyl Oxalates Enabling Formation of Alkylated and Arylated Quaternary Carbon Centers. J. Am. Chem. Soc. 2019, 141, 820-824.

(10) Selected allylic examples, see: (a) Evans, P. A.; Oliver, S. Regio- and enantiospecific rhodium-catalyzed allylic substitution with an acyl anion equivalent. Org. Lett. 2013, 15, 5626-5629. (b) Feng, C.; Kaneko, Y.; Kobayashi, Y. Construction of quaternary carbon centers by using substitution of $\gamma, \gamma$-disubstituted secondary allylic picolinates with alkylcopper reagents. Tetrahedron Lett. 2013, 54, 4629-4632. (c) Zhang, H. H.; Zhao, J. J.; Yu, S. Enantioselective Allylic Alkylation with 4-Alkyl-1,4dihydro-pyridines Enabled by Photoredox/Palladium Cocatalysis. J. Am Chem. Soc. 2018, 140, 16914-16919.

(11) Wang, Z.; Yin, H.; Fu, G. C. Catalytic enantioconvergent coupling of secondary and tertiary electrophiles with olefins. Nature 2018, 563, 379383.

(12) Wu, L.; Yang, G.; Zhang, W. Ni-Catalyzed Enantioconvergent Coupling of Epoxides with Alkenylboronic Acids: Construction of Oxindoles Bearing Quaternary Carbons. CCS Chem. 2019, 1, 623-631.

(13) Zhou, Q.; Cobb, K. M.; Tan, T.; Watson, M. P. Stereospecific Cross Couplings to Set Benzylic, All-Carbon Quaternary Stereocenters in High Enantiopurity. J. Am. Chem. Soc. 2016, 138, 12057-12060.

(14) Harris, M. R.; Hanna, L. E.; Greene, M. A.; Moore, C. E.; Jarvo, E. R. Retention or inversion in stereospecific nickel-catalyzed cross-coupling of benzylic carbamates with arylboronic esters: Control of absolute stereochemistry with an achiral catalyst. J. Am. Chem. Soc. 2013, 135, 33033306.
(15) Zhou, Q.; Srinivas, H. D.; Dasgupta, S.; Watson, M. P. Nickelcatalyzed cross-couplings of benzylic pivalates with arylboroxines: Stereospecific formation of diarylalkanes and triarylmethanes. J. Am. Chem. Soc. 2013, 135, 3307-3310.

(16) Basch, C. H.; Cobb, K. M.; Watson, M. P. Nickel-Catalyzed Borylation of Benzylic Ammonium Salts: Stereospecific Synthesis of Enantioenriched Benzylic Boronates. Org. Lett. 2016, 18, 136-139.

(17) Zhang, S. Q.; Taylor, B. L. H.; Ji, C. L.; Gao, Y.; Harris, M. R.; Hanna, L. E.; Jarvo, E. R.; Houk, K. N.; Hong, X. Mechanism and Origins of LigandControlled Stereoselectivity of Ni-Catalyzed Suzuki-Miyaura Coupling with Benzylic Esters: A Computational Study. J. Am. Chem. Soc. 2017, 139, 12994-13005.

(18) Tasker, S. Z.; Standley, E. A.; Jamison, T. F. Recent advances in homogeneous nickel catalysis. Nature 2014, 509, 299-309.

(19) Diccianni, J. B.; Diao, T. Mechanisms of Nickel-Catalyzed CrossCoupling Reactions. Trends Chem. 2019, 1, 830-844.

(20) The list price from Strem Chemicals, Inc., was $\$ 94 / \mathrm{mol}$ for $\mathrm{Ni}(\mathrm{acac})_{2} \cdot \mathrm{xH}_{2} \mathrm{O}$ vs. $\$ 3,015 / \mathrm{mol}$ for $\mathrm{NiCl}_{2} \cdot \mathrm{DME}$ on April 2, 2020.

(20) The list price from Strem Chemicals, Inc., was $\$ 94 / \mathrm{mol}$ for $\mathrm{Ni}(\mathrm{acac})_{2} \cdot \mathrm{xH}_{2} \mathrm{O}$ vs. $\$ 3,015 / \mathrm{mol}$ for $\mathrm{NiCl}_{2} \cdot \mathrm{DME}$ on April 2, 2020 .

(21) (a) Feng, C.; Kobayashi, Y. Allylic substitution for construction of a chiral quaternary carbon possessing an aryl group. J. Org. Chem. 2013, 78, 3755-3766. (b) Potter, B.; Edelstein, E. K.; Morken, J. P. Modular, catalytic enantioselective construction of quaternary carbon stereocenters by sequential cross-coupling reactions. Org. Lett. 2016, 18, 3286-3289. (c) Cobb, K. M.; Rabb-Lynch, J. M.; Hoerrner, M. E.; Manders, A.; Zhou, Q.; Watson, M. P. Stereospecific, Nickel-Catalyzed Suzuki-Miyaura CrossCoupling of Allylic Pivalates to Deliver Quaternary Stereocenters. Org. Lett. 2017, 19, 4355-4358.

(22) See the Supporting Information for the determination of the absolute configuration of products 11 and 20. The configuration of other products was determined by analogy.

(23) (a) Johnson, J. B.; Rovis, T. More than bystanders: The effect of olefins on transition-metal-catalyzed cross-coupling reactions. Angew. Chem., Int. Ed. 2008, 47, 840-871. (b) ref. 6. (c) Derosa, J.; Kleinmans, R.; Tran, V. T.; Karunananda, M. K.; Wisniewski, S. R.; Eastgate, M. D.; Engle, K. M. Nickel-Catalyzed 1,2-Diarylation of Simple Alkenyl Amides. J. Am Chem. Soc. 2018, 140, 17878-17883. (d) Gao, P.; Chen, L.-A.; Brown, M. K. Nickel-Catalyzed Stereoselective Diarylation of Alkenylarenes. J. Am. Chem. Soc. 2018, 140, 10653-10657.

(24) (a) Nattmann, L.; Saeb, R.; Nöthling, N.; Cornella, J. An air-stable binary Ni(0)-olefin catalyst. Nat. Catal. 2020, 3, 6-13. (b) Tran, V. T.; Li, Z.-Q.; Apolinar, O.; Derosa, J.; Joannou, M. V.; Wisniewski, S. R.; Eastgate, M. D.; Engle, K. M. Ni(COD)(DQ): An Air-Stable 18-Electron Nickel(0)Olefin Precatalyst. Angew. Chem., Int. Ed. 2020, DOI: 10.1002 /anie. 202000124 . 
Authors are required to submit a graphic entry for the Table of Contents (TOC) that, in conjunction with the manuscript title, should give the reader a representative idea of one of the following: A key structure, reaction, equation, concept, or theorem, etc., that is discussed in the manuscript. Consult the journal's Instructions for Authors for TOC graphic specifications.

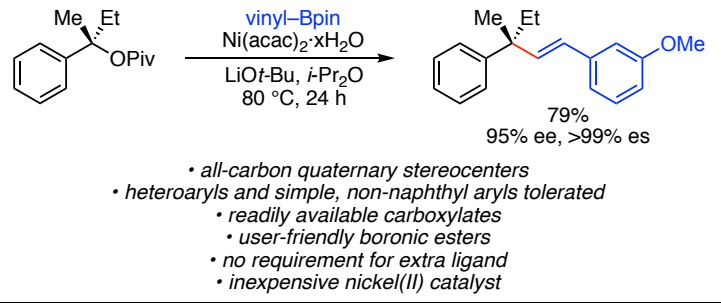

